\title{
Adoption of the Mobile Campus in a Cyber University
}
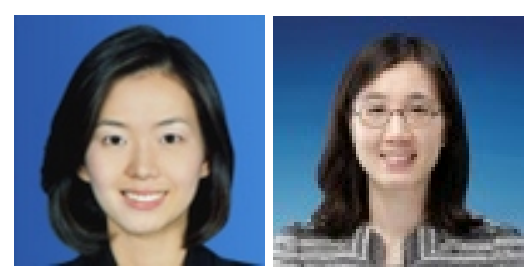

Insook Han and Seungyeon Han

Hanyang Cyber University, South Korea

\section{Abstract}

The advantages of mobile technologies have not been lost on higher education institutions, and they have tried to provide educational services through the use of mobile learning management system (LMS). However, offering such services does not necessarily mean that the students will adopt the new technology. Thus, the purpose of this study was to examine what factors facilitate and hinder the students' adoption of the mobile campus. The study was based on the diffusion of innovation model and compared the perceptions of mobile LMS users and nonusers. Eighty-five students in a cyber university responded to the survey, and the results revealed that even though nonusers perceived the advantages of using mobile LMS, they did not adopt the system because of its complexity and resistance. A discussion and the implications for further development of mobile LMS followed.

Keywords: Mobile LMS; diffusion of innovation; cyber university 


\section{Mobile Campus Innovation in a Cyber University}

The widespread use of mobile phones and other portable and wireless devices has been changing the landscape of technology-supported learning. Many universities and educational institutions have made efforts to develop mobile applications and/ or mobile campuses for academic, social, and administrative support. Mobile applications increase accessibility to learning contents and activities, and questions/answers, especially for students who are taking e-learning courses. It has turned out that mobile technologies are well aligned with strategic educational goals, such as improving student retention and achievement, helping differentiate learning needs, and reaching learners who would otherwise not have the opportunity to participate in education (Kukulska-Hulme et al., 2009).

A few years ago, cyber universities introduced the mobile campus, although not all functions in the traditional web-based learning management system (LMS) were implemented in the early stages. The mobile campus has evolved according to what was learned from trial applications. The features of the current mobile campus include attending online courses, posting questions, checking messages, and monitoring academic calendars. Moreover, mobile application is connected with traditional LMS; that is, learning activity that occurred in the mobile campus is recorded as regular attendance and participation in the traditional one. Therefore, learners are normally observed attending online courses and posting messages in bulletin boards while commuting or at any other time they are available.

However, no matter how promising innovative technologies are, in this case, mobile applications for learning, not all students readily take to them. Learners have different attitudes toward the use of new technology, and the mere act of adopting it cannot change the learning experience. We need to carefully examine what factors facilitate and hinder the students' adoption of the mobile campus so that we can further develop it to support learning.

This study aimed to investigate how students perceived the mobile campus initiative of a cyber university. This purpose is addressed by two research questions. First, what opportunities and challenges do students encounter in adopting the mobile campus? Second, what are the differences between the traditional learning management system and the mobile campus? 


\section{Literature Review}

\section{Mobile Learning}

Mobile learning has been defined as learning facilitated by mobile devices such as mobile phones, table PCs, and personal media players (Herrington \& Herrington, 2007; Valk, Rashid, \& Elder, 2010) in both formal and informal educational settings (Quinn, 2011; Traxler, 2007, 2010). Increased awareness of the potentials of mobile learning has expanded the body of related literature. From the meta analysis of more than 160 articles published between 2003 and 2010, Wu et al. (2012) found that research has focused (in descending order) on evaluating the effects of mobile learning, designing mobile learning systems, investigating the affective domain during mobile learning, and evaluating the influence of learner characteristics on the mobile learning process. In addition, it has been found that $86 \%$ of the studies that were reviewed reported positive outcomes (Wu, Wu, Kao, Lin, \& Huang, 2012).

However, in previous studies, the use of mobile devices was limited to supplementary activities to the regular learning processes, such as engaging in online interaction with peers and instructors using a specific social media application (Gikas \& Grant, 2013; Hoffman, 2009; Pang, 2009), creating and sharing video/audio files, taking photographs, and receiving or sending text messages (Vavoula, Sharples, Rudman, Meek, \& Lonsdale, 2009), and using other miscellaneous functions such as calculators or dictionaries embedded in mobile devices (Taleb \& Sohrabi, 2012). Students want more than these fragmentary uses that partially enhance learning activities designed within a certain course; they want to be able to access learning contents, such as reading materials or multimedia resources (Al-Mushasha, 2010; Cheon, Lee, Crooks, \& Song, 2012), discuss course content, communicate with teachers, and access course information (Cheon et al., 2012). These activities for course works are typically provided through learning management systems that are commonly available in the Web and accessed with computers. Indeed, current mobile technologies can help meet the students' needs for increased accessibility to course work through mobile devices, so that higher education institutions are now offering LMS with mobile devices. However, research on the use of mobile LMS remains insufficient.

\section{Mobile LMS in Higher Education}

A traditional LMS is usually a Web-based platform that enables the planning and delivery of learning events for both virtual and instructor-driven face-to-face classes (Greenberg, 2002). Through the LMS, students are able to access their course materials, take online tests, access their grades, share resources with other students or an instructor, upload assignments, and collaborate with classmates (Cavus, 2011; Watson \& Ahmed, 2004). Recent technological advances, such as wireless transmission and mobile devices, allow learners to access the LMS anytime and anywhere (Andronico et al., 2004; Corlett, Sharples, Chan, \& Bull, 2004), thus enhancing learner mobility and 
the accessibility of information and learning activities (Andronico et al., 2004). Mobile LMS also facilitates interaction and collaboration between learners, and learners and instructors (Goh \& Kinshuk, 2006).

Since college students use mobile devices more than K-12 students do (Traxler, 2007), mobile learning has been most frequently used in higher education contexts (Hwang \& Tsai, 2011; Wu et al., 2012). In particular, the advantages of mobile LMS and growing number of mobile users on university campuses have increased the awareness of mobile LMS in higher education institutions. One survey conducted among university IT professionals across the United States reported that more than two-thirds of the participants agreed/strongly agreed that mobile LMS was an important part of their campus plan to enhance instructional resources and campus services (Green, 2010). However, in reality, mobile LMS deployment is still in its early phase (Green, 2010), and research on the use of mobile LMS has not been actively conducted yet. Few studies have addressed pertinent issues, such as the students' perceptions of the use of mobile LMS (Cavus, 2011), different usage behaviors between mobile and traditional LMS users (Modritshcer, Neumann, \& Brauer, 2012), and the design and development of mobile LMS including assessment tools (Riad \& El-Ghareeb, 2008) and context-aware mobile technologies (i.e., sensors and cameras) for detecting the context of the users' situation and providing the appropriate university services and information (Lehsten, Zender, Lucke, \& Tavangarian, 2010). However, there is little research exploring what makes students choose to use mobile LMS in the first place. Hence, considering that students play decisive roles in the diffusion of mobile LMS throughout university campuses, what hinders or facilitates their adoption of new learning technologies should be addressed.

\section{Factors Related to Mobile LMS Adoption: From the Diffusion of Innovations Model}

Various factors affect the adoption of innovative technologies. In this study, the innovative technology is mobile LMS, which is gaining acceptance in higher education settings. Thus, a service provider should know what factors influence the students' adoption of a particular innovation technology to improve decision-making processes and quality.

A well-known framework for innovation studies is the diffusion of innovations (Rogers, 1995) model, which provides a paradigm for understanding the adoption of innovations and acceptance or resistance to change (Dooley, 1999; Rogers, 2000; Adams, 2002; Bennett \& Bennett, 2003; Petherbridge, 2007). According to this model, there are five innovation attributes that affect the decision to adopt/reject an innovation: Relative Advantage, Compatibility, Complexity, Trialability, and Observability. Relative Advantage is the extent to which the innovation is perceived as better than what is currently available. If mobile LMS provides a more effective learning management, students will likely use it. Compatibility is how well the innovation matches existing values and models. The degree to which the functionalities of mobile LMS are matched 
with the existing PC and Web-based LMS affects its adoption. Complexity is the extent to which the innovation is easy to comprehend and use; mobile LMS should afford ease of use. Trialability is the degree to which a potential user can experiment with the innovation without having to commit to use it. Thus, the greater the opportunity for students to try out mobile LMS, the easier it is for them to evaluate its effectiveness and ultimately adopt it. Finally, Observability is the extent to which a potential adopter can see the usefulness of the innovation in his/her situation. For example, if students in higher education institutions can easily observe other students' use of mobile LMS and realize its educational benefits, they would be more willing to adopt it.

The perception of the attributes of innovation might differ between those who have already adopted mobile LMS and those who have not. Hence, in this study, the perceptions of users and nonusers will be compared to determine which attributes foster or hinder the adoption of mobile LMS. Also, by analyzing the limitations of current mobile LMS from the perspective of users' perceptions, the implications for the future development of mobile LMS can be discussed.

\section{Methods}

\section{Participants}

The participants, recruited from A Cyber University located in Seoul, South Korea, were undergraduates majoring in Educational Technology, Social Welfare, Counseling Psychology, Child Studies and Education, and Hospitality and Tourism Management. The students were invited to voluntarily take part in a survey without monetary compensation or credit reward. Only the complete responses from 85 students were included in the data analysis.

Around two-thirds of the participants were female, 26 to 45 years old-the typical composition of the student population in most South Korean cyber universities (Suh \& Kim, 2013). Further, half of the participants were in $3^{\text {rd }}$ year. Students in cyber universities are adult learners, most of whom work during daytime; they were not able to pursue a face-to-face four-year college course when they were between 19 and 25 years old (typical age of university student). Cyber university students start to take up four-year courses when they are in their middle 20s or later, or transfer to cyber universities after graduating from two-year college courses, which thus makes the $3^{\text {rd }}$ year population the largest among universities. In terms of majors, $79 \%$ of the participants were from the two largest departments in A Cyber University: $46 \%$ were in Social Welfare and 33\%, in Counseling Psychology. Meanwhile, 13\% were in Hospitality and Tourism Management; 7\%, in Child Studies and Education; and 1\%, in Educational Technology (Table 1). 
Table 1

Participants' Background Information

\begin{tabular}{|c|c|c|c|}
\hline & & Frequency & Percent \\
\hline \multirow{2}{*}{ Gender } & Female & 66 & 77.6 \\
\hline & Male & 19 & 22.4 \\
\hline \multirow{5}{*}{ Age } & $19-25$ & 6 & 7.1 \\
\hline & $26-35$ & 31 & 36.5 \\
\hline & $36-45$ & 28 & 32.9 \\
\hline & $46-55$ & 17 & 20.0 \\
\hline & Above 56 & 3 & 3.5 \\
\hline \multirow{4}{*}{ Year in college } & 1st year & 1 & 1.2 \\
\hline & $2^{\text {nd }}$ year & 23 & 27.1 \\
\hline & $3^{\text {rd }}$ year & 46 & 54.1 \\
\hline & $4^{\text {th }}$ year & 15 & 17.6 \\
\hline \multirow{5}{*}{ Major } & Educational Technology & 1 & 1.2 \\
\hline & Social Welfare & 39 & 45.9 \\
\hline & Counseling Psychology & 28 & 32.9 \\
\hline & $\begin{array}{l}\text { Child Studies and } \\
\text { Education }\end{array}$ & 6 & 7.1 \\
\hline & $\begin{array}{l}\text { Hospitality and Tourism } \\
\text { Management }\end{array}$ & 11 & 12.9 \\
\hline
\end{tabular}

\section{Mobile LMS}

The mobile LMS used in this study was the official learning management system of A Cyber University, which managed learners' activities through a mobile application in line with a traditional Web-based LMS. Mainly, the mobile LMS provided online learning contents, monitored learning activities, fostered instructor-learner interaction, and provided information. The specific functions of each category are shown in Table 2. 
Table 2

Main Features of the Mobile LMS

\begin{tabular}{lll}
\hline Main features & & Functions \\
\hline Main page & Providing information & About the university \\
& & Admissions \\
& Student services: academic calendar, \\
& FAQ, technical services, personal \\
& authentication certificate \\
& & Community services: announcement \\
& & board, bulletin board \\
\hline Virtual classroom & Providing multimedia & MP3 file format - VOD, AOD \\
& learning contents & AVI file format - electronic board, \\
& & traditional board, e-Stream \\
\cline { 2 - 3 } & Monitoring learning & Attendance \\
& activities & Learning time \\
& & Learning progress \\
\cline { 2 - 3 } & Facilitating interaction & Instructor-learner interaction \\
& - Announcement \\
& - Q\&A \\
& $-1: 1$ consulting \\
& Learner-learner interaction \\
& - Bulletin board \\
\hline
\end{tabular}

With mobile LMS, students have access to a virtual classroom that is connected to the virtual classroom in the traditional LMS. In the mobile virtual classroom, the learning contents are delivered in streaming audio or video format, depending on the type of lecture developed (Figure 1). The students' learning record in the mobile LMS, such as attendance, learning time, and learning progress, can be synchronized with the traditional LMS at the same time. To enable this monitoring feature, students have to log in to the system with a personal authentication certificate, which is meant to prevent proxy attendance. 

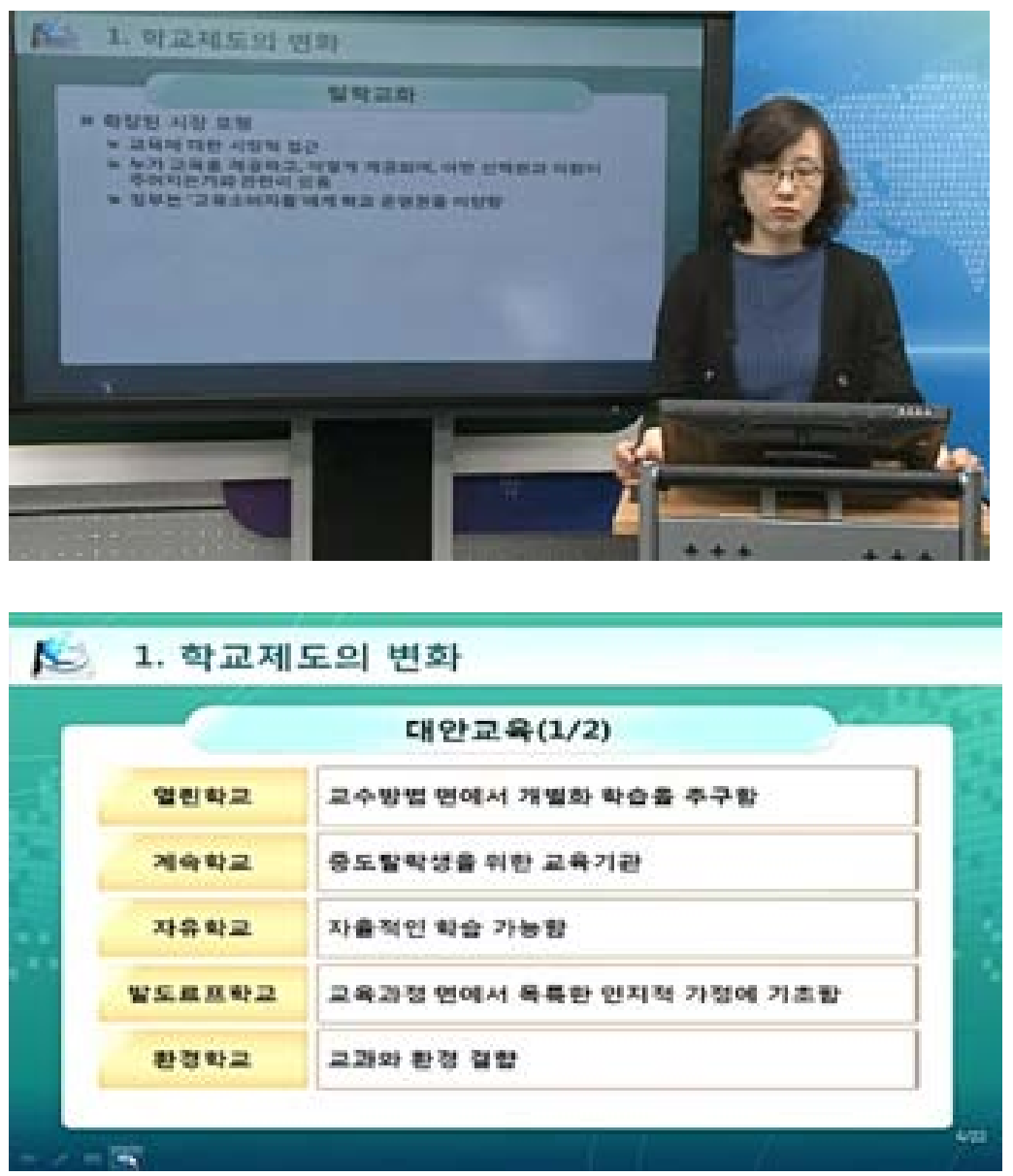

Figure 1. Screenshot of the video lecture on mobile LMS.

In the mobile virtual classroom (Figure 2), diverse interaction opportunities are offered as well. Instructors can post assignment deadlines, test schedules, and other courserelated announcements on the announcement board. They can also answer the students' questions through 1:1 consulting and Q\&A. The 1:1 consulting feature is for closed inquiries, which are not available to other students, while the Q\&A is for open inquiries, which are shared with all other students in the same classroom. Students can also interact with their classmates through the bulletin board. All records of interactions in mobile LMS are sychronized with the traditional Web-based LMS. However, some of the features offered in the traditional LMS (e.g., online discussions, chatting, and surveys; quizzes; test-taking; and assignment submission) are not yet available in the mobile LMS. 


\begin{tabular}{|c|c|c|c|c|}
\hline 학교소개 & 얍힉얀내 & 학생서비스 & 커뮤니티 & 강의실 \\
\hline 강의 & 공지 & Q\&A & 게시판 & 상담 \\
\hline
\end{tabular}

(01반) 웹기반학습프로그래밍

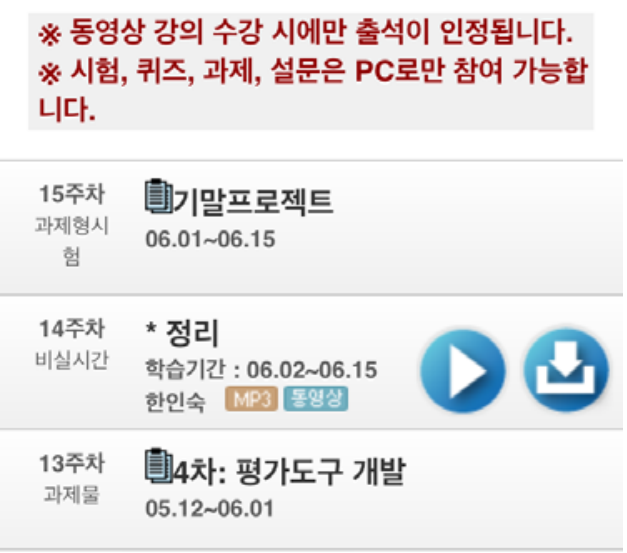

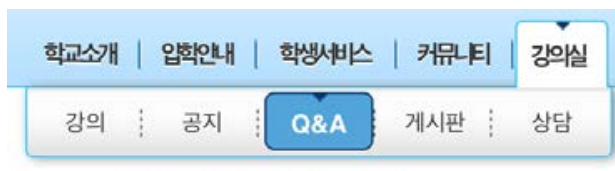

(01반) 웹기반학습프로그래밍

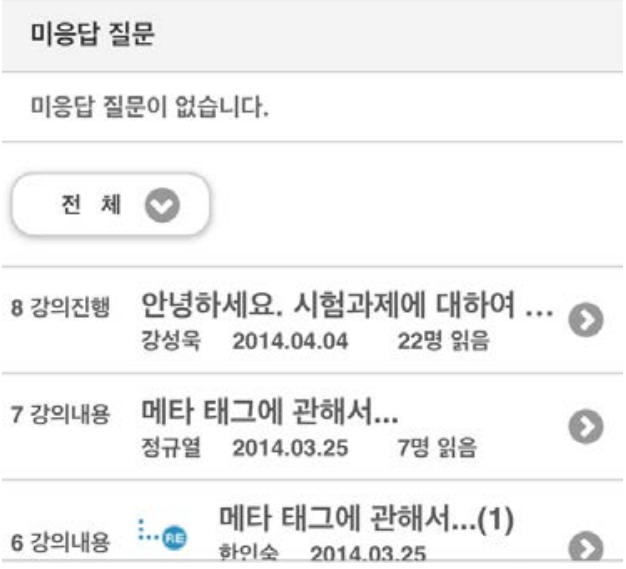

Figure 2. Lecture lists (left) and Q\&A (right) in the virtual classroom.

In the main page of the mobile LMS, students can access all information about the university, admissions, student services, and community services. Student services include the academic calendar, FAQ, technical services, and detailed information about the personal authentication certificate. Community services offer the opportunity to socially interact with other students in the same major by posting on the bulletin board.

\section{Survey Instrument}

A survey instrument was developed to examine the factors influencing learners' adoption of mobile LMS. Firstly, an open-ended survey was conducted with 160 students in the Department of Educational Technology, who were asked to spontaneously answer the questions based on their experiences. The survey had 11 items, which asked about the type of mobile technology they used; the time, place, and purposes of using mobile LMS; for nonusers, their reasons for not using mobile LMS; intention of using mobile LMS; and suggestions for improving the system. Of the 160 students, 89 responded. The responses were classified according to the five categories proposed in the diffusion of innovations model, which resulted in a total of 41 items. Relative Advantage had 5 items; Compatibility, 16; Complexity, 7; Trialability, none; and Observability, 7. The remaining 6 items were classified as Resistance, a category that was added based on the participants' answers. Resistance is related to the psychological resistance to the adoption of new technology because the innovation forces a change of behavior (Hall \& Hord, 2006). Since no items related to Trialability emerged, the survey did not include this category. 
The 41 preliminary items were then reviewed by a panel of experts to secure content validity. Seven experts in educational technology and distance education numerically rated each survey item in a five-point Likert scale as to how much it represented the category it belonged to. Also, they described how each item should be qualitatively revised so that it would clearly present what it was intended to. The content validity ratio (CVR) was then calculated based on the experts' numerical ratings. Items with a CVR of less than .70 were removed, recategorized, or revised to reflect the experts' reviews, which brought the total down to 35 items: five in Relative Advantage, four in Compatibility, four in Complexity, nine in Observability, and seven in Resistance.

Reliability tests were performed on the finalized survey items in each category; the survey was conducted on 135 students from the Introduction to Educational Technology course in the spring of 2013. The Cronbach's alpha values of .70, .95, .77, .92, and .71 for Relative Advantage, Compatibility, Complexity, Observability, and Resistance, respectively, were all acceptable or higher for the survey items' internal consistency (Kline, 2000).

\section{Procedures}

Before conducting the main survey for this study, a survey instrument was developed following the procedures shown in Figure 3. Then, using the survey instrument, the main study was conducted by distributing the survey to students registered in courses. An online survey link was provided in the cyber classroom and the students were invited to participate for two weeks. The purpose of the study was explained to them before starting the survey, and only those who clicked the "start" button could participate in the online survey.

\begin{tabular}{|l|l|l|l|l|}
\hline Open-ended survey & $\rightarrow$ & Experts' review & $\rightarrow$ & Reliability test \\
\hline With 11 items & & With 41 items & & With 35 items \\
$\begin{array}{l}\text { Received 89 responses } \\
\text { Repared a } \\
\text { preliminary survey } \\
\text { with 41 items }\end{array}$ & & $\begin{array}{l}\text { Prepared a revised } \\
\text { survey with 35 items }\end{array}$ & & $\begin{array}{l}\text { Received 135 responses } \\
\text { Finalized the survey } \\
\text { with 35 items }\end{array}$ \\
\hline
\end{tabular}

Figure 3. Procedures in developing a survey instrument. 


\section{Results}

\section{Use of Mobile Device and Mobile LMS}

Of the 85 students who participated in the survey, almost $80 \%$ were using mobile devices, such as mobile phones or smart pads. However, only half of the participants said that they were currently using mobile LMS for learning (Table 3).

Table 3

Number of Participants Using Mobile Devices and Mobile LMS

\begin{tabular}{llll}
\hline & & Frequency & Percent \\
\hline \multirow{2}{*}{ Use of mobile devices } & Yes & 67 & 78.8 \\
\cline { 2 - 4 } & No & 18 & 21.2 \\
\hline \multirow{2}{*}{ Use of mobile LMS } & Yes & 41 & 48.2 \\
\cline { 2 - 4 } & No & 44 & 51.8 \\
\hline
\end{tabular}

An interesting tendency was found in the descriptive statistics of the participants' answers (Table 4). Among the five factors examined in this study, Relative Advantage, Compatibility, and Observability are considered positive factors that influence the adoption of new technology, while Complexity and Resistance are considered negative factors. Mobile LMS users were expected to perceive relative advantage, compatibility, and observability more than nonusers did. In contrast, nonusers were expected to perceive more complexities in and resistance to using mobile LMS than the users. Unexpectedly, however, nonusers seemed to have a higher degree of perception regarding the three positive factors. Even though they were not using mobile LMS, the nonusers still anticipated that using mobile LMS would give them easier and faster access to the university system and information. Also, nonusers tended to perceive more convenience in the mobile LMS's being in line with the traditional Web-based LMS. While users did expect mobile LMS to give them more opportunities to interact with professors, participate in campus life, and be more punctual for academic deadlines, nonusers exhibited a somewhat higher level of perception for these positive factors. Regarding the two negative factors, users perceived less complexity and resistance than nonusers did, as expected. In other words, nonusers thought that using mobile LMS was difficult and complex, as well as uncomfortable and worrisome. 
Table 4

Means and Standard Deviations of the Participants' Answers to the Survey

\begin{tabular}{|c|c|c|c|c|}
\hline \multirow{2}{*}{ Survey items } & \multicolumn{2}{|c|}{ Users $(\mathrm{N}=41)$} & \multicolumn{2}{|c|}{ Nonusers $(\mathrm{N}=44)$} \\
\hline & $\mathrm{M}$ & SD & $\mathrm{M}$ & SD \\
\hline \multicolumn{5}{|l|}{ Relative advantage } \\
\hline Being able to use spare time to attendcourses with mobile LMS & 4.20 & 1.10 & 3.91 & .96 \\
\hline $\begin{array}{l}\text { Being able to use spare time to post on bulletin board with } \\
\text { mobile LMS }\end{array}$ & 3.10 & 1.16 & 3.84 & 1.01 \\
\hline Being able to use mobile LMS on the move & 4.27 & 1.10 & 4.00 & 1.10 \\
\hline Easier access to mobile LMS & 3.37 & 1.26 & 3.48 & 1.07 \\
\hline Faster access to academic schedules with mobile LMS & 3.63 & .99 & 3.82 & .99 \\
\hline \multicolumn{5}{|l|}{ Compatibility } \\
\hline $\begin{array}{l}\text { Convenient to check attendance with mobile LMS in line with } \\
\text { Web-based LMS }\end{array}$ & 4.07 & 1.13 & 3.95 & .89 \\
\hline $\begin{array}{l}\text { Convenient to use 1:1 consulting and Q\&A with mobile LMS in } \\
\text { line with Web-based LMS }\end{array}$ & 3.56 & .95 & 3.91 & 83 \\
\hline $\begin{array}{l}\text { Convenient to use bulletin board with mobile LMS in line with } \\
\text { Web-based LMS }\end{array}$ & 3.68 & .91 & 3.91 & .83 \\
\hline $\begin{array}{l}\text { Convenient to use community services with mobile LMS in line } \\
\text { with Web-based LMS }\end{array}$ & 3.63 & .94 & 3.91 & 86 \\
\hline \multicolumn{5}{|l|}{ Complexity } \\
\hline Difficult to download mobile LMS application & 2.80 & 1.08 & 3.00 & 1.08 \\
\hline Difficult to login with authentication certificate & 2.49 & 1.31 & 3.34 & 1.12 \\
\hline Difficult to check lectures available in mobile LMS & 2.63 & 1.28 & 2.95 & 1.08 \\
\hline Difficult to use mobile LMS interface & 2.66 & 1.06 & 2.89 & .97 \\
\hline \multicolumn{5}{|l|}{ Observability } \\
\hline Better grade due to mobile LMS & 2.98 & .91 & 2.80 & 1.00 \\
\hline Better learning due to mobile LMS & 3.10 & 1.07 & 2.98 & .93 \\
\hline More frequent access to a virtual classroom with mobile LMS & 3.56 & 1.27 & 3.41 & 1.15 \\
\hline More interaction with a professor with mobile LMS & 2.88 & .90 & 3.27 & .97 \\
\hline More active participation in campus life due to mobile LMS & 3.24 & 1.02 & 3.39 & .99 \\
\hline More enjoyable campus life due to mobile LMS & 3.14 & 1.01 & 3.34 & .94 \\
\hline Being less late or absent for class with mobile LMS & 3.17 & 1.14 & 3.68 & 1.07 \\
\hline More punctual for assignment deadlines with mobile LMS & 3.02 & 1.01 & 3.48 & .99 \\
\hline Fewer missed academic schedules due to mobile LMS & 3.20 & 1.17 & 3.59 & 1.00 \\
\hline \multicolumn{5}{|l|}{ Resistance } \\
\hline Feeling worried about the payment & 2.59 & 1.38 & 3.43 & 1.30 \\
\hline Preferring a PC or laptop to a mobile phone & 3.49 & 1.33 & 3.84 & 1.12 \\
\hline $\begin{array}{l}\text { Feeling worried about getting interrupted (with calls or } \\
\text { messages) while listening to a lecture }\end{array}$ & 3.34 & 1.35 & 3.73 & 11 \\
\hline Feeling worried about battery usage & 3.24 & 1.43 & 3.95 & 1.08 \\
\hline Feeling that the network is reliable ${ }^{\mathrm{a}}$ & 3.54 & 1.10 & 2.91 & .98 \\
\hline Not being accustomed to mobile learning & 2.73 & 1.07 & 3.14 & 1.19 \\
\hline Feeling of not being in the learning & 2.88 & 1.19 & 3.11 & 1.10 \\
\hline
\end{tabular}

a reverse-coded item; in bold: items that are perceived higher by nonusers among those representing positive factors

\section{Perception of Factors Influencing the Adoption of Mobile LMS: Differences Between Users and Nonusers}

To investigate whether mobile LMS users and nonusers had different perceptions of the factors influencing the adoption of mobile LMS, an independent samples t-test was 
conducted on Relative Advantage, Compatibility, Complexity, Observability, and Resistance. Table 5 presents the descriptive statistics for each factor influencing mobile LMS and t-test results comparing the perceptions of the users and nonusers. Both groups showed similar levels of perception of Relative Advantage, Compatibility, and Observability. However, users and nonusers showed different perceptions of Complexity $(\mathrm{t}=-2.123, \mathrm{p}<.05)$ and Resistance $(\mathrm{t}=-2.313, \mathrm{p}<.05)$, both of which were statistically significant.

Table 5

Mean, Standard Deviation, and T-Test Results for the Perceptions of Mobile LMS Users and Nonusers

\begin{tabular}{|c|c|c|c|c|c|c|}
\hline & & $\mathrm{N}$ & $\mathrm{M}$ & SD & $\mathrm{t}$ & sig. \\
\hline \multirow{2}{*}{ Relative advantage } & Users & 41 & 18.56 & 3.93 & \multirow{2}{*}{-.550} & \multirow{2}{*}{.584} \\
\hline & Nonusers & 44 & 19.05 & 4.18 & & \\
\hline \multirow{2}{*}{ Compatibility } & Users & 41 & 14.95 & 3.21 & \multirow{2}{*}{-1.040} & \multirow{2}{*}{.301} \\
\hline & Nonusers & 44 & 15.68 & 3.26 & & \\
\hline \multirow{2}{*}{ Complexity } & Users & 41 & 10.59 & 3.54 & \multirow{2}{*}{-2.123} & \multirow{2}{*}{$.037 *$} \\
\hline & Nonusers & 44 & 12.18 & 3.40 & & \\
\hline \multirow{2}{*}{ Observability } & Users & 41 & 28.29 & 7.32 & \multirow{2}{*}{-1.026} & \multirow{2}{*}{.308} \\
\hline & Nonusers & 44 & 29.93 & 7.40 & & \\
\hline \multirow{2}{*}{ Resistance } & Users & 41 & 21.80 & 5.12 & \multirow{2}{*}{-2.313} & \multirow{2}{*}{$.023^{*}$} \\
\hline & Nonusers & 44 & 24.11 & 4.05 & & \\
\hline
\end{tabular}

$* \mathrm{p}<.05$

To further examine where the two groups differed in the category of Complexity, an independent samples t-test was conducted in terms of four items (Table 6). A general tendency showed that mobile LMS nonusers perceived the use of mobile LMS as more complex than users did. In particular, nonusers perceived the use of an authentication certificate for attendance and test-taking as more complex, and this difference was statistically significant $(\mathrm{t}=-3.240, \mathrm{p}<.05)$.

Table 6

Mean, Standard Deviation, and T-Test Results for Complexity

\begin{tabular}{|c|c|c|c|c|c|c|}
\hline & & $\mathrm{N}$ & $\mathrm{M}$ & S.D. & $\mathrm{t}$ & sig. \\
\hline \multirow{2}{*}{$\begin{array}{l}\text { Difficult to download mobile LMS } \\
\text { application }\end{array}$} & Users & 41 & 2.80 & 1.08 & \multirow{2}{*}{-.834} & \multirow{2}{*}{.407} \\
\hline & Nonusers & 44 & 3.00 & 1.08 & & \\
\hline \multirow{2}{*}{$\begin{array}{l}\text { Difficult to login with the } \\
\text { authentication certificate }\end{array}$} & Users & 41 & 2.49 & 1.31 & \multirow{2}{*}{-3.240} & \multirow{2}{*}{$.002^{*}$} \\
\hline & Nonusers & 44 & 3.34 & 1.12 & & \\
\hline \multirow{2}{*}{$\begin{array}{l}\text { Difficult to check lectures } \\
\text { available in mobile LMS }\end{array}$} & Users & 41 & 2.63 & 1.28 & \multirow{2}{*}{-1.244} & \multirow{2}{*}{.217} \\
\hline & Nonusers & 44 & 2.95 & 1.08 & & \\
\hline \multirow{2}{*}{$\begin{array}{l}\text { Difficult to use mobile LMS } \\
\text { interface }\end{array}$} & Users & 41 & 2.66 & 1.06 & \multirow{2}{*}{-1.033} & \multirow{2}{*}{.305} \\
\hline & Nonusers & 44 & 2.89 & .97 & & \\
\hline
\end{tabular}

$* \mathrm{p}<.05$ 
Also, regarding Resistance, an independent samples t-test was performed to further investigate what kinds of psychological resistance nonusers perceived more than users did. There was a general tendency for nonusers to perceive more resistance, which means they were more worried about payments, getting interrupted, battery usage, and network conditions; preferred other technologies, such as a PC or laptop, to mobile phones for learning; were unaccustomed to mobile learning; and felt they were not being in the learning with mobile phones (Table 7). In particular, nonusers perceived more resistance to payments, battery usage, and the network condition; the levels were statistically significant at $\mathrm{t}=-2.913(\mathrm{p}<.005), \mathrm{t}=2.576(\mathrm{p}<.012)$, and $\mathrm{t}=2.779(\mathrm{p}<$ .007), respectively.

Table 7

Mean, Standard Deviation, and T-Test Results for Resistance

\begin{tabular}{|c|c|c|c|c|c|c|}
\hline & & $\mathrm{N}$ & $\mathrm{M}$ & $\overline{\mathrm{SD}}$ & $\mathrm{t}$ & sig. \\
\hline \multirow{2}{*}{$\begin{array}{l}\text { Feeling worried about the } \\
\text { payment }\end{array}$} & Users & 41 & 2.59 & 1.38 & \multirow{2}{*}{-2.913} & \multirow{2}{*}{$.005^{*}$} \\
\hline & Nonusers & 44 & 3.43 & 1.30 & & \\
\hline \multirow{2}{*}{$\begin{array}{l}\text { Preferring a PC or laptop to a } \\
\text { mobile phone }\end{array}$} & Users & 41 & 3.49 & 1.33 & \multirow{2}{*}{-1.330} & \multirow{2}{*}{.187} \\
\hline & Nonusers & 44 & 3.84 & 1.12 & & \\
\hline \multirow{2}{*}{$\begin{array}{l}\text { Feeling worried about getting } \\
\text { interrupted (with calls or } \\
\text { messages) while listening to } \\
\text { lectures }\end{array}$} & Users & 41 & 3.34 & 1.35 & \multirow{2}{*}{-1.433} & \multirow{2}{*}{.156} \\
\hline & Nonusers & 44 & 3.73 & 1.11 & & \\
\hline \multirow{2}{*}{$\begin{array}{l}\text { Feeling worried about battery } \\
\text { usage }\end{array}$} & Users & 41 & 3.24 & 1.43 & \multirow{2}{*}{-2.576} & \multirow{2}{*}{$.012 *$} \\
\hline & Nonusers & 44 & 3.95 & 1.08 & & \\
\hline \multirow{2}{*}{ Feeling the network is reliable ${ }^{a}$} & Users & 41 & 3.54 & 1.10 & \multirow{2}{*}{2.779} & \multirow{2}{*}{$.007 *$} \\
\hline & Nonusers & 44 & 2.91 & .98 & & \\
\hline \multirow{2}{*}{$\begin{array}{l}\text { Not being accustomed to } \\
\text { mobile learning }\end{array}$} & Users & 41 & 2.73 & 1.07 & \multirow{2}{*}{-1.640} & \multirow{2}{*}{.105} \\
\hline & Nonusers & 44 & 3.14 & 1.19 & & \\
\hline \multirow{2}{*}{$\begin{array}{l}\text { Feeling of not being in the } \\
\text { learning }\end{array}$} & Users & 41 & 2.88 & 1.19 & \multirow{2}{*}{-.948} & \multirow{2}{*}{.346} \\
\hline & Nonusers & 44 & 3.11 & 1.10 & & \\
\hline
\end{tabular}

$* \mathrm{p}<.05$; r reverse-coded item

\section{Discussion}

The results of the descriptive statistics showed that mobile LMS nonusers' perception of Relative Advantage, Compatibility, and Observability was similar to or somewhat higher than that of traditional Web-based LMS users. This implies that mobile LMS nonusers also acknowledge the advantages and positive factors of using mobile LMS. However, they are still reluctant to adopt this new system, and the reason could be found in their perception of the challenges of using the system, such as Complexity and Resistance. One of the biggest challenges about the change is dealing with resistance. Hall and Hord (2006) addressed several reasons for resistance, two of which are closely related to the result of this study. The first reason for resistance works through the sense of loss of having to stop doing something that is familiar and comfortable. The second form of 
resistance is grounded in having serious questions about whether the innovation will really be an improvement, due to a limited understanding of the new technology. That is, even though nonusers appreciate the new opportunities that the mobile LMS can create, their perception of the system's complexity and their psychological resistance exceed their appreciation of it, which thus discourages them from adopting the mobile LMS.

Conversely, even though users perceive advantages less in the mobile LMS, they nevertheless use it because they are not deterred by resistance or its complexity. Therefore, to diffuse this new LMS throughout the campuses, universities not only advertise the advantages of using it but also focus on reducing the complexities and psychological resistance that hamper users. This result is consistent with previous research, which has determined that perceived ease of use and organizational support significantly affect the adoption of mobile devices in learning (Chang \& Kim, 2011).

The unexpected result of mobile LMS users' low perception of the positive factors may be addressed by discussions on the future directions of mobile LMS design and development. It is possible that users' perception is lower because they found that the seemingly very advantageous factors were, in fact, not what they had expected. For example, users perceived that attending courses while on the move was a relative advantage, but they thought that participating in the course and checking academic schedules were not relatively more useful than the traditional Web-based LMS. In all likelihood, neither did they find the features related to academic and social interaction with professors and other students more useful than those of the Web-based LMS. This indicates that users opt for mobile LMS mainly to attend courses while they are on the move; they do not use it for the other purposes that were also considered possible positive factors for adopting mobile LMS. This tendency implies that the features implemented in mobile LMS in line with traditional Web-based LMS were not particularly useful for the students. In other words, current mobile LMS is a smaller version of the Web-based virtual classroom that provides similar features, but only in different mobile devices. It is thus not attractive to users other than for attending courses. With this in mind, we need to reconsider how we can design mobile LMS to reflect more advantages drawn from the devices' uniqueness. One example could be a mobile LMS designed to support self-directed learning (Chung, 2009). In Chung's study (2009), the mobile LMS supports students' metacognition, motivation, and behavioral monitoring through specific mobile functions, including goal setting, planning, monitoring, self-assessment, interaction and feedback, time management, academic planner, and question-and-answer with SMS. Other studies propose mobile assessment with SMS functions (Raid \& El-Ghareeb, 2008) and a context-aware mobile LMS that incorporates mobile-specific context-aware mobile technologies (i.e., sensors and cameras) for detecting the context of the users' situation and providing the appropriate university services and information (Lehsten et al., 2010). 


\section{Conclusion}

The result of the study yields timely information for further development and implementation of mobile LMS. Based on the comparison between users and nonusers of mobile LMS, this study provides implications on how the system can be further developed by adopting users' demands. For future development, as mentioned earlier, the mobile LMS should be grounded in the nature of mobile devices, and not just duplicate what the Web-based LMS currently provides for learning. Also, the mobile LMS should be adaptive to the developmental status of the mobile device, as well as the individual learner's needs.

This study also has several limitations that lead to future studies. Since this study was conducted in one cyber university in Korea during the beginning stages of the development of mobile LMS, the result of the study cannot be over-generalized to all kinds of mobile learning supported by different tools and technologies. In addition, from the methodological perspective, this study only adopted a quantitative approach and in-depth interviews with learners would provide more insights to identify their perception and beliefs regarding the innovation. Using mobile campus is personalized experience and situated in specific context, therefore understanding individual students' perception is useful to identify factors facilitating adoption of innovation. In this way, the results of this study will be reinforced with what makes learners adopt or resist the innovation. Finally, the instructors' perspective in using the mobile LMS should also be examined in future research. Recent studies on adoption of mobile learning have been limited on investigating students' perception (e.g., Bao, Xiong, Hu, \& Kibelloh, 2013; Irby \& Strong, 2013; Park, Nam, \& Cha, 2012). However, university instructors are important users of mobile LMS and their perception and facilitation can affect students' use of mobile LMS (McLoughlin \& Lee, 2010). Therefore, future research should examine what factors facilitate university instructors' adoption of mobile LMS. 


\section{References}

Adams, N. B. (2002). Educational computing concerns of postsecondary faculty. Research on Technology in Education, 34(3), 285 - 303.

Al-Mushasha, F. N. (2010, November). Has the time for university's mobile learning come? Determining students' perception. In 12th International Conference on Information Integration and Webbased Application \& Services, Paris, France.

Andronico, A., Carbonaro, A., Colazzo, L., Molinari, A., Ronchetti, M., \& Trifonova, A. (2004). Designing models and services for learning management systems in mobile settings. In Mobile and ubiquitous information access (pp. 90-106). Springer Berlin Heidelberg.

Bao, Y., Xiong, T., Hu, Z., \& Kibelloh, M. (2013). Exploring gender differences on general and specific computer efficacy in mobile learning adoption. J ournal of Educational Computing Research, 49(1), 111-132.

Bennett, J ., \& Bennett, L. (2003). A review of factors that influence the diffusion of innovation when structuring a faculty training program. Internet and Higher Education, 6, 53-63.

Cavus, N. (2011). Investigating mobile devices and LMS integration in higher education: Student perspectives. Procedia Computer Science, 3, 1469-1474.

Chang, I., \& Kim, J . (2011). An analysis of structural model on the employees' learning intention using smart devices. J ournal of Vocational Education \& Training, 14(3), 105-126.

Cheon, J ., Lee, S., Crooks, S. M., \& Song, J . (2012). An investigation of mobile learning readiness in higher education based on the theory of planned behavior. Computers \&Education, 59(3), 1054-1064.

Chung, A. K. (2008). Development of a mobile platform (mobile embedded in LMS) to support self-regulated learning. Unpublished doctoral dissertation. Ewha Womans University

Corlett, D., Sharples, M., Chan, T., \& Bull, S. (2004). A mobile learning organiser for university students. In Wireless and Mobile Technologies in Education, 2004. Proceedings. The 2nd IEEE International Workshop on (pp. 35-42). IEEE.

Dooley, K. E. (1999). Towards a holistic model for the diffusion of educational technologies: an integrative review of educational innovation studies. Educational Technology \& Society, 2(4), 35-45. 
Gikas, J ., \& Grant, M. M. (2013). Mobile computing devices in higher education:

Student perspectives on learning with cellphones, smartphones \& social media. The Internet and Higher Education, 19, 18-26.

Goh, T., \& Kinshuk, D. (2006). Getting ready for mobile learning -adaptation perspective. J ournal of Educational Multimedia and Hypermedia, 15(2), 175198.

Green, K. C. (2010). The 2010 campus computing survey. Retrieved October, 6, 2012.

Greenberg, L. (2002). LMS and LCMS: What's the difference. Learning Circuits, 31(2).

Hall, G. E., \&Hord, S. M. (2006). Implementing change: Patterns, principles, and potholes (2nd ed.). NewYork: Pearson Education.

Herrington, A., \&Herrington, J . (2007). Authentic mobile learning in higher education. In AARE 2007 International Educational Research Conference, 28 November 2007, Fremantle, Western Australia.

Hoffman, E. S. (2013). Social media and learning environments: Shifting perspectives on the locus of control. in education, 15(2).

Hwang, G. J ., \& Tsai, C. C. (2011). Research trends in mobile and ubiquitous learning: A review of publications in selected journals from 2001 to 2010. British J ournal of Educational Technology, 42(4), E65-E70.

Irby, T. L., \& Strong, R. (2013). Agricultural education students' acceptance and selfefficacy of mobile technology in classroom. NACTA J ournal, 82-87.

Kline, P. (2000). The handbook of psychological testing (2nd ed.). London: Routledge.

Kukulska-Hulme, A., Sharples, M., Milrad, M., Arnedillo-Sánchez, I., \& Vavoula, G. (2009). Innovation in mobile learning: A European perspective. International J ournal of Mobile and Blended Learning (IJ MBL), 1(1), 13-35.

Lehsten, P., Zender, R., Lucke, U., \& Tavangarian, D. (2010, March). A service-oriented approach towards context-aware mobile learning management systems. In Pervasive Computing and Communications Workshops (PERCOM Workshops), 2010 8th IEEE International Conference on (pp. 268-273). IEEE.

McLoughlin, Cl, Lee, M. J . W. (2010). Personalized and self-regulated learning in the Web 2.0 era: International exemplars of innovative pedagogy using social software. Australasian J ournal of Educational Technology, 26(1), 28-43. 
Modritscher, F., Neumann, G., \& Brauer, C. (2012, J uly). Comparing LMS usage behavior of mobile and web users. In Advanced Learning Technologies (ICALT), 2012 IEEE 12th International Conference on (pp. 650-651). IEEE.

Pang, L. (2009). A survey of web 2.0 technologies for classroom learning. The International J ournal for Learning, 16(9), 743- 759.

Park, Y. S., Nam, M., \& Cha, S., (2012). University students' behavioral intention to use mobile learning: Evaluating the technology acceptance model. British J ournal of Educational Technology, 43(4), 592-605.

Petherbridge, D. T. (2007). A concerns-based approach to the adoption of web-based learning management systems. Unpublished doctoral dissertation. North Carolina State University.

Quinn, C. N. (2011). Designing mLearning: Tapping into the mobile revolution for organizational performance. J ohn Wiley \& Sons.

Raid., A. M., \& El-Ghareeb, H. A. (2008). A service oriented architecture to integrate mobile assessment in learning management systems. Turkish OnlineJ ournal of Distance Education, 9(2).

Rogers, D. L. (2000). A paradigm shift: Technology integration for higher education in the new millennium. Educational Technology Review, 13,19-33.

Rogers, E.. M.(1995). Diffusion of innovations. The Free Press, New York.

Suh, S., \& Kim, S.(2013). Study on policy for an entrance quota of cyber universities. Seoul, Korea: Korea Educational Information and Research Service.

Taleb, Z., \& Sohrabi, A. (2012). Learning on the move: The use of mobile technology to support learning for university students. Procedia-Social and Behavioral Sciences, 69, 1102-1109.

Traxler, J . (2007). Defining, discussing, and evaluating mobile learning: The moving finger writes and having writ... International Review of Research in Open \& Distance Learning, 8(2), 1-11.

Valk, J. H., Rashid, A. T., \& Elder, L. (2010). Using mobile phones to improve educational outcomes: An analysis of evidence from Asia. International Review of Research in Open \& Distance Learning, 11(1).

Vavoula, G., Sharples, M., Rudman, P., Meek, J ., \&Lonsdale, P. (2009). Myartspace: Design and evaluation of support for learning with multimedia phones between classrooms and museums. Computers \& Education, 53(2), 286-299. 
Watson, J., \&Ahmed, P. K. (2004). Learning in the age of global information technology: Development of a generic architecture for an advanced learning management system. Campus-Wide Information Systems, 21(1), 4-21.

Wu, W. H., Jim Wu, Y. C., Chen, C. Y., Kao, H. Y., Lin, C. H., \& Huang, S. H. (2012). Review of trends from mobile learning studies: A meta-analysis. Computers \& Education, 59(2), 817-827.

(C) Han and Han

\section{Athabasca University $\mathbf{I}$}

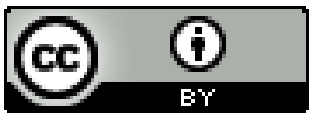

This work is licensed under a Creative Commons Attribution 4.0 International License. 